$$
\text { DOE/ER/61011-.T3 }
$$

\title{
TEMPERATURE CORRECTIONS FOR THE VIZ AND VAISALA RADIOSONDES
}

\author{
JAMES K. LUERS \\ UNIVERSITY OF DAYTON RESEARCH INSTITUTE
}

\author{
ROBERT E. ESKRIDGE \\ NATIONAL CLIMATIC DATA CENTER
}

JANUARY 1994

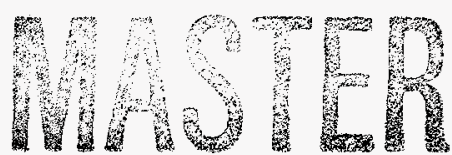

\section{DISCLAIMER}

This report was prepared as an account of work sponsored by an agency of the United States Government. Neither the United States Government nor any agency thereof, nor any of their employees, makes any warranty, express or implied, or assumes any legal liability or responsibility for the accuracy, completeness, or usefulness of any information, apparatus, product, or process disclosed, or represents that its use would not infringe privately owned rights. Reference herein to any specific commercial product, process, or service by trade name, trademark, manufacturer, or otherwise does not necessarily constitute or imply its endorsement, recommendation, or favoring by the United States Government or any agency thereof. The views and opinions of authors expressed herein do not necessarily state or reflect those of the United States Government or any agency thereof. 


\section{DISCLADMER}

Portions of this document may be illegible in electronic iroge products. Images are produced from the best arailable original doccoments. 


\section{ABSTRACT}

The NWS VIZ radiosonde and the Vaisala RS-80 radiosondes are used worldwide to obtain upper air measurements of atmospheric temperature and moisture. The temperature measured by each sensor is not equal to the atmospheric temperature due to solar and infrared irradiation of the sensor, heat conduction to the sensor from its attachment points, and radiation emitted by the sensor. Presently, only the RS-80 radiosonde applies corrections to the sensor temperature to compensate for these heating sources, and this correction is only considered to be a function of solar angle and pressure.

Temperature correction models VIZCOR (VIZ sonde) and VAICOR (Vaisala RS-80 sonde) have been developed that derive the atmospheric temperature from the sensor temperature, taking into account all significant environmental processes that influence the heat transfer to the sensor. These models have been validated by comparing their corrected profiles with atmospheric temperature profiles derived from the NASA multi-thermistor radiosonde. All three radiosondes were flown on the same balloon during the PREFRS radiosonde intercomparison. Excellent agreement has been found between all profiles up to an altitude of $30 \mathrm{~km}$. Since the significant error sources in the VIZCOR, VAICOR and multi-thermistor techniques are largely independent agreement between all profiles, implies the corrected sensor profiles are providing an unbiased estimate of the true atmospheric temperature. 


\section{TEMPERATURE CORRECTIONS FOR VIZ AND VAISALA RADIOSONDES}

\section{Background}

Current numerical climate models predict strong surface warming in the polar regions and marked cooling in the stratosphere when the model atmospheric $\mathrm{CO}_{2}$ concentration is doubled. Verification or refutation of these model results requires the existence of reliable long-term data records. The National Climatic Data Center (NCDCNDCA) and the All-Union Research Institute of Hydro Meteorological Information (AURIHMINWDCB), of Russia have initiated a joint project "Comprehensive Aerological Reference Data Set" (CARDS). The goal of the CARDS project is to produce an upper-air data set based on radiosonde and pibal observations, suitable for evaluating climate models and detecting global change. The CARDS project is: producing a long-term (1960-1990) daily data set of concomitant upper-air and surface synoptic observations using the entire global collection of upper-air and co-located surface observations.

CARDS consists of three data bases: first, there is a "raw" data base consisting of all the upper air reports in the form the data is received (no corrections applied); secondly, there is a quality controlled (QC) data base. The third data base is the one in which detected biases in the data have been flagged or removed from the quality controlled data base.

Systematic errors or biases occur in upper air data as a result of radiational heating of the sensor, a change in the data reduction method or a change in the radiosonde instrument that affects the sensor measurements. The magnitude of the error in the upper-air temperatures has been estimated to be 1 to 3 degrees Celsius with current radiosondes. Errors of this magnitude are larger than any century-scale predicted climatic change for most areas. Therefore, these errors must be identified and removed from the climatic data set.

Several methods are being used to detect systematic radiosonde errors: accurate station histories, mathematical-physical models, and statistical techniques. Unfortunately, station histories are, at 
best, incomplete and in many cases nonexistent.

A keystone of the CARDS research program is the development of methods to identify systematic errors (biases) in the upper-air data using statistical techniques and to develop temperature correction models for the most widely used radiosondes of the 1960-1990 period.

The systematic error is due to radiational, convective and conductive effects on the radiosonde instruments and housing, and is particularly amenable to correction by mathematical-physical models. The detailed design of temperature adjustment model is the subject of this paper. Applying the model to correct the temperature requires a knowledge of where and when the radiosondes were used, and environmental conditions such as cloud cover and solar angle.

International radiosonde comparison experiments are another means of estimating biases in radiosonde measurements. Unfortunately, comprehensive standardization of all radiosonde biases would require comparisons of the full suite of radiosonde types ever used. This would not be feasible even if all instrument types were still available. Since radiosonde biases are time and location dependent, tests would have to be carried out in many portions of the world and at several times of day. Nonetheless, the studies conducted by Nash (1984), Nash and Schmidlin (1987), and Ivanov, et al. (1992) are very useful. These studies show the likely magnitudes of the errors, and how the biases vary with the time response of the instruments and with the physical properties of the sonde. These studies also provide data from which temperature and humidity correction models for the various radiosondes can be validated. Intercomparison data obtained from the recent Potential REFerence RadioSonde (PREFRS) tests in Crawley, England, 1992, has been used to validate the temperature correction models for the VIZ and Vaisala radiosondes described in this paper. 


\section{TEMPERATURE CORRECTIONS FOR VIZ AND VAISALA RADIOSONDES}

Introduction

The measurement of atmospheric temperature by every radiosonde instrument is contaminated by heating from sources other than the air itself. Solar and infrared radiation, heat conduction to the sensor through its attachment points, and infrared radiation emitted by the sensor are heat scurces and sinks that make the temperature of the sensor different from that of the air which it is trying to measure. Thus, a correction is required for each instrument in order to deduce the atmospheric temperature from the temperature of the radiosonde sensor. For most radiosondes this correction is small $\left(<0.5^{\circ} \mathrm{C}\right)$ at altitudes below 15 kilometers but can become quite significant (several degrees) at altitudes between 20 and 30 kilometers. Some radiosondes utilize a correction table to compensate for sensor heating while other radiosondes do not. For many of the early radiosondes, the temperature correction was on the order of 3 to $10^{\circ} \mathrm{C}$ while for today's leading radiosondes, this correction has been reduced to less than $3^{\circ} \mathrm{C}$. The correction, however, varies from day-to-day, depending upon solar angle, cloud cover, ground temperature, humidity, and other parameters. None of the correction tables used with today's radiosondes take into account all the important parameters that influence the temperature correction. Thus, to produce a compatible stratospheric temperature data base from radiosonde instruments requires the development of a correction technique for each radiosonde that takes into account those parameters that significantly affect the temperature of the radiosonde sensor.

A model has been developed that calculates the temperature correction for the VIZ instrument used by the National Weather Service. This model VIZCOR, calculates the temperature correction as a function of environmental parameters (Luers, 1989). It has been tested and validated by comparing its predicted temperature correction with the correction directly measured by the NASA multi-thermistor radiosonde (Schmidlin and Luers, 1988; Luers and Schmidlin, 1992) The VIZCOR model requires the use of the LOWTRAN7 atmospheric transmission code (Kneizys, et. al. 1988) to establish the radiation environment experienced by the sensor along its ascent profile. Recently, a model similar to VIZCOR has 
been developed for the Vaisala RS-80 radiosonde. The VAlsala CORrection model, VAICOR, was developed to estimate the temperature correction for the RS-80 sonde. A recent PREFRS radiosonde intercomparison experiment has provided data from which comparisons can be made between corrected profiles from the VIZ, RS-80, and multi-thermistor radiosondes (described in the following paragraphs). A schematic of each Radiosonde is shown in Figure 1.

The PREFRS (Potential REFerence Radiosonde) intercomparison radiosonde tests were conducted in Crawley, England during February and March 1992. Carried aboard each balloon flight were up to 5 different types of radiosondes that transmitted temperature and other profile data to ground receiving stations. The radiosonde instruments included the Vaisala RS-80 sonde, a multi-thermistor AIR sonde, a multi-thermistor VIZ sonde, and a Swiss and United Kingdom radiosonde. The multi-thermistor radiosondes contained three rod thermistors having different surface coatings. These radiosondes were being tested and evaluated as a potential reference radiosonde. One of the three thermistor on each multithermistor radiosonde was the standard white coated VIZ thermistor used operationally for NWS VIZ radiosonde flights.

The RS-80, the AIR, and the VIZ multi-thermistor radiosondes provided temperature sensor data from which 5 atmospheric temperature profiles were derived. From each (AIR and VIZ) multi-thermistor sonde two atmospheric temperature profiles were produced: one derived from the temperature differences between the three coated thermistors, and a second by correcting the white coated VIZ thermistor using the VIZCOR model. The fith profile was derived by correcting the temperature of the RS-80 bead sensor using the VAICOR model. Since considerable independence exists between the techniques used in deriving the various profiles, agreement between all profiles would give a high level of confidence that the composite profile is an accurate estimate of the true atmospheric temperature. The following sections describe how each radiosonde temperature correction profile is generated and the significant sources of error in the corrected profiles. 


\section{THE MULTI-THERMISTOR RADIOSONDE}

The multi-thermistor radiosonde has been developed at NASA Wallops Flight Facility as a reference instrument to measure the absolute temperature of the atmosphere (Schmidlin, 1986, 1992). The instrument utilizes three rod thermistors, each prepared with a different surface coating, to deduce the temperature of the atmosphere. A fourth thermistor is included to provide redundancy in one of the measurements. The white (standard $V(Z)$, black, and aluminum paint coatings each have different absorption and emission properties and thus provide somewhat different temperature measurements as the radiosonde rises through the atmosphere. The three different temperature measurements allows a system of heat balance equations for each thermistors to be solved simultaneously for the temperature of the air, and for the solar and infrared irradiation of the thermistors.

The heat balance equation for the standard VIZ rod thermistor has been derived by Luers (1989) as:

$$
-H\left(T_{s}-T\right) A-\sigma \varepsilon_{s} A T_{s}^{4}+\varepsilon_{s} R+\alpha_{s} S+\left.2 \pi r_{w}^{2} k_{w} \frac{d T_{w}}{d l_{s}}\right|_{l=0}=m c \frac{d T_{s}}{d t}
$$

Applying this derivation to the aluminum and black rod thermistors with different absorption and emission properties gives:

$$
\begin{aligned}
& -H\left(T_{a}-T\right) A-\sigma \varepsilon_{a} A T_{a}^{-1}+\varepsilon_{a} R+\alpha_{2} S+\left.2 \pi r_{w}^{2} k_{w} \frac{d T_{w}}{d l_{a}}\right|_{l=0}=m c \frac{d T_{a}}{d t} \\
& -H\left(T_{b}-T\right) A-\sigma \varepsilon_{b} A T_{b}^{4}+\varepsilon_{b} R+\alpha_{b} S+\left.2 \pi r_{w}^{2} k_{w} \frac{d T_{w}}{d l_{b}}\right|_{w=0}=m c \frac{d T_{b}}{d t}
\end{aligned}
$$

where:

$\mathrm{H}=$ Convective heat transfer coefficient

$T_{s}, T_{a}, T_{b}=$ Temperature of the standard, aluminum, and black thermistors, respectively

$\alpha_{S}, \alpha_{a}, \alpha_{b}=$ Solar absorbtivity of the standard, aluminum, and black thermistors, respectively

$\varepsilon_{s}, \varepsilon_{a}, \varepsilon_{b}=$ Emissivity of the standard, aluminum, and black thermistors, respectively 


$$
\begin{array}{ll}
T_{W} & =\text { Temperature of the wire } \\
T & =\text { The air temperature } \\
A & =\text { Surface area of the thermistor } \\
R & =\text { Infrared radiation irradiating the thermistor } \\
S & =\text { Solar radiation irradiating the thermistor } \\
\sigma & =\text { Stefan Boltzman constant } \\
r_{W} & =\text { Radius of the thermistor lead wires } \\
k_{W} & =\text { Thermal conductivity of the lead wires } \\
I_{m} & =\text { Length of the lead wires } \\
m & =\text { Mass of the thermistor } \\
c & =\text { Specitic heat capacity of the thermistor } \\
t & =\text { Time }
\end{array}
$$

This system of equations assumes that the mass, dimensions and orientation of all thermistors are identical. Equations ( 1 through 3 ) contain all the significant terms that control the heat transfer into and out of each rod thermistor. The solar and infrared radiation parameters, $S$ and $R$, respectively, include the direct, reflected, and scattered radiation coming from all view directions.

To solve equations (1 through 3 ) for the atmospheric temperature, $T$, the temperature of the wire $T_{w}$ at its interface with the thermistor must be determined for each thermistor. This is achieved by solving a heat balance equation for the lead wire that is very similar in form to equations ( 1 through 3 ). The reader is referred to (Luers, 1989) for a derivation and discussion of the lead wire heat balance equations.

The air temperature $T$, is determined by solving equations ( 1 through 3 ) simultaneously for the unknowns $T, R$, and $S$. Thus, the ambient temperature is a direct output from processing the multithermistor radiosonde data. As a by-product, the temperature correction for the standard (white VIZ) rod thermistor is given by $\Delta T=T_{S}-T$. The other parameters in equations ( 1 through 3 ) are determined as follows.

The heat transfer coefficient, $\mathrm{H}$, is calculated from the empirical Nusselt number equation for a cylinder in laminar crossflow given by Fan and Keswani (1972) as a function of Reynolds number. 
The Reynolds number, $R e$, is calculated using the balloon rise rate and the atmospheric density measured at each point in the flight. The thermistor radius is provided by the manufacturer. The specific heat capacity of the thermistor, $c$, and thermal conductivity of the lead wires, $k_{W}$, were taken from (Ballard and Rubio, 1968). The solar absorbtivity,$\alpha$, and infrared emissivity, $\varepsilon$, of each thermistor were determined by laboratory measurements.

A theoretical error analysis was performed (Luers, 1992) to establish the accuracy of the atmospheric temperature that is measured by the 3-thermistor radiosonde. This error analysis consisted of a sensitivity study to determine the influence of each parameter in equations ( 1 through 3 ) on $\Delta T$; and then using nominal values for the certitude (accuracy) of each parameter the accuracy of $\Delta T$ was deduced. The most significant error sources were found to arise from the inaccuracy in the absorbtivity measurement of the aluminum thermistor, and the random error in the measurement of the temperature of each thermistor. If the random temperature measurement error can be maintained less than 0.2 degrees and the absorbtivity known to within 0.03 , then the resulting temperature correction should be accurate to $\pm 0.3^{\circ} \mathrm{C}$. Additional errors of significance will arise with this system if the assumption that the diameters of the three thermistors being equal, is violated.

\section{VIZ RADIOSONDE}

The VIZ radiosonde, utilizing a white coated rod thermistor, has been the primary radiosonde instrument used by the NWS for measuring atmospheric temperature since the early 1960's. The white coated thermistor is $4 \mathrm{~mm}$ long with diameter $1.2 \mathrm{~mm}$. It is well known that at high altitudes, above $20 \mathrm{~km}$, the thermistor temperature is warmer than that of the atmosphere during the daytime and colder at night time (Ballard and Rubio, 1968; Luers, 1990). Presently, no corrections are made to the VIZ radiosonde data to compensate for this temperature error.

The temperature correction for the $V I Z$ rod thermistor can be estimated by utilizing the radiosonde measurements of altitude, thermistor temperature, balloon rise rate, and pressure, along with independent 
estimates of the amount of solar and infrared irradiation of the thermistor as a function of the environment. The irradiation estimates are derived using the LOWTRAN7 atmospheric transmission model with the appropriate input values that describe the surface and atmospheric conditions. The VIZ temperature CORrection model is called VIZCOR. When predicting the radiosonde temperature correction by this method, the heat transfer equation for the rod thermistor equation (4) is solved directly for the air temperature from which the temperature correction $\Delta T=T_{S}-T$ is derived. The heat transfer equation for the rod thermistor previously given by equation (1) can be rewritten as:

$$
\mathrm{mc} \frac{\mathrm{dT}_{\mathrm{s}}}{\mathrm{dt}}=\mathrm{q}_{\mathrm{abs}}-\sigma \varepsilon_{\mathrm{s}} \mathrm{AT}_{\mathrm{s}}^{4}-\mathrm{AH}\left(\mathrm{T}_{\mathrm{s}}-\mathrm{T}\right)+\left.2 \pi \mathrm{r}_{\mathrm{w}}^{2} \mathrm{k}_{\mathrm{w}} \frac{\mathrm{dT}_{\mathrm{w}}}{\mathrm{dl}}\right|_{\mathrm{L}=0}
$$

where the term $q_{a b s}$ is the combined solar and infrared radiation terms of equation (1). This term is calculated from the radiation properties of the thermistor and the LOWTRAN7 output data. The remaining heat transfer terms are evaluated in the same manner used to evaluate this equation with the multithermistor radiosonde.

The total absorbed radiation term, $\mathrm{q}_{\mathrm{abs}}$ including both the solar $(\alpha \mathrm{S})$ and infrared (ER) contributions, is given by:

$$
\mathrm{q}_{\mathrm{abs}}=\iint_{\lambda} \int_{\theta} \mathrm{I}(\lambda, \theta, \phi) \alpha(\lambda) \mathrm{Ap}(\mathrm{r}, \mathrm{l}, \theta) \mathrm{d} \lambda \mathrm{d} \theta \mathrm{d} \phi \quad 0.25 \leq \lambda \leq 28 \mu
$$

where:

$\mathrm{I}(\lambda, \theta, \phi) \quad=$ the intensity of radiation of wavelength $\lambda$ irradiating the thermistor from the direction whose azimuth angle is $\phi$, and elevation angle is $\theta$

$\alpha(\lambda) \quad=$ the wavelength dependent absorption coefficient of the thermistor

$\operatorname{Ap}(r, 1, \theta) \quad=$ the average presented area of the cylindrical rod thermistor during one revolution as viewed from the direction $\theta$

The integration is performed over the solar and infrared wavelength spectrum from $0.25 \mu<\lambda<28$ $\mu$. The average presented area, $A p$, for the thermistor is that of a cylinder as a function of view angle. From the vertical direction, the presented area always equals the cross sectional area of the cylinder while 
a horizontal view of a rotating cylinder reduces the average presented area to $65 \%$ of the cross sectional area (Talbot, 1972). The intensity of radiation $\mathrm{I}(\lambda, \theta$,$) is derived by running the LOWTRAN7 atmospheric$ transmission code under the specified environmental conditions associated with the radiosonde flight.

The error in the temperature correction arises from errors in all parameters of equation (4). In general; the contribution that a source makes to the error in the temperature correction varies with altitude and with the magnitude of the temperature corrections itself. The influence of each error source on the error on the temperature correction has been assessed by a sensitivity analysis using both day and night flight conditions (Luers, 1992). The results from this study indicate that the temperature correction is most sensitive to inaccuracies in the convective heat transfer coefficient, and the thermistor and lead wire dimensions. The latter controls the heat conduction through the lead wires. The error in the temperature correction is also sensitive to inaccuracies in the specification of cloud cover (including cirrus), solar angle, and surface temperature that are inputs to the LOWTRAN7 model which specify the radiation environment.

In contrast to the multi-thermistor radiosonde, the significant error sources for the VIZCOR predicted correction profile are different from those that influence the multi-thermistor profile. For the multithermistor radiosonde, the solar absorbtivity of the aluminum thermistor and the thermistor temperature measurements themselves are the significant sources of error. These are not significant error sources in the temperature correction profile predicted by the VIZCOR model. In contrast, the VIZCOR sensitive parameters; the heat transfer coefficient, the thermistor and lead wire dimensions, and the environmental parameters have no discernible influence on the temperature profile derived by the multi-thermistor radiosonde. Thus, the parameters that cause errors in the corrected atmospheric temperature profiles are very different using the two different methodologies. Consequently, if agreement is good between the corrected temperature profiles derived from the two methods, there is high confidence that the profiles are measuring and modeling the true atmospheric temperature. 


\section{VAISALA RS-80 RADIOSONDE}

Vaisala radiosondes have been used at many world-wide locations for upper air measurements since about 1940. Early Vaisala radiosondes (Vaisala, 1967) used a bimetal strip to sense the temperature of the atmosphere. The bimetal strip was used on the RS-11, RS-12, RS-13 and RS-15 radiosondes that were commonly flown up until the introduction of the RS-18 sonde in 1976. The RS-18 and RS-21 sondes used a bimetal ring as a replacement for the bimetal strip as a means of reducing the temperature correction resulting from radiation (Antikainen, 1973). These radiosondes were used until 1981 when the capacitive bead temperature sensor and the RS-80 sonde were introduced (Vaisala Ref \#435). This radiosonde is in worldwide use today. A model has been developed to estimate the temperature correction for the Vaisala RS-80 radiosonde.

The heat balance equation for the capacitive bead temperature sensor can be written in the same form equation (4) as that for the VIZ rod thermistor. However, several parameter values in the heat balance equation, as well as a change in the form of some of the heat transfer terms is required. The parameters that differ are: the sensor dimensions, surface area, mass, specific heat, presented area, absorbtivity, emissivity, lead wire dimensions, and the convective heat transfer coefficient.

The geometric shape of the Vaisala bead sensor is approximated as a cylinder with cones attacned to both ends (Vaisala, REF. NO. A935). Measurements of the dimension of the thermistor have been made using a precision instrument that magnifies the image. Using the measured thermistor and lead wire dimensions, theory and software have been developed to calculate the average presented area

of the thermistor and lead wires viewed from any direction (Luers, 1993). This information is used in equation (5) to calculate the amount of solar and infrared radiation absorbed from each direction.

The solar and infrared absorption and emission properties of the bead coating, as provided by Vaisala, are $\varepsilon=0.02$ for the emissivity and $\alpha=0.11$ for the solar absorbtivity. The mass and specific heat of the coated bead were estimated based upon the size and material composition of the bead.

The convective heat transfer coefficient is required for a cylindrical sensor with conical ends that is 
tilted about $35^{\circ}$ from the vertical so that the vertical airflow interacts with an irregular shaped object. Since no analytic heat transfer coefficient is known for the aifflow over this object an approximate heat transfer expression was developed. It was assumed that the heat transfer coefficient can be approximated as that of a sphere, with appropriate diameter. The nominal sphere diameter was considered as the average of the maximum and minimum dimensions of the sensor as viewed in the direction of the airflow motion. The derived expression is:

$$
\begin{aligned}
& \mathrm{H}=\mathrm{Nu} \cdot \mathrm{k} / \mathrm{d}_{\mathrm{ave}} \\
& \mathrm{N}_{\mathrm{u}}=2+\left(0.4 \mathrm{Re}^{1 / 2}+0.06 \mathrm{Re}^{2 / 3}\right) \mathrm{Pr}^{0.4}
\end{aligned}
$$

where:

$$
\begin{aligned}
& \text { Re }=\text { Reynolds Number } \quad 3.5<\operatorname{Re}<76000 \\
& \operatorname{Pr}=\text { Prandtl Number } \quad 0.71<\operatorname{Pr}<380 \\
& d_{\text {ave }}=\left(d+d^{\prime}\right) / 2 \\
& d=\text { maximum dimension of sensor viewed vertically } \\
& d^{\prime}=\text { minimum dimension of sensor viewed vertically }
\end{aligned}
$$

Of the parameters used in equation (4) for the VAICOR model, those that are not accurately known are the convective heat transfer coefficient $\mathrm{H}$ and the solar absorbtivity of the aluminized bead. The solar absorbtivity value is uncertain because laboratory measurement of absorbtivity are traditionally made on a coated flat plate specimen irradiated at an incidence angle of $15^{\circ}$ to $20^{\circ}$ from the vertical. The absorbtivity of an aluminum coating on a curved surface such as a cylinder or sphere is a function of the angle of incidence, with more absorption occurring at low grazing angles. For this reason, the absorbtivity of the aluminized bead sensor is expected to be somewhat larger than $\alpha=0.11$ measured value.

The VAICOR model was tuned to establish the proper values of $\alpha$ and $\mathrm{H}$. A 'calibration set' of intercomparison day and night flights was established and the VAICOR model run with modified values of $\alpha$ and $H$ until agreement was established between corrected RS-80, VIZ, and multi-thermistor profiles. A tuned value of $\alpha=0.15$ and the $H$ value of equation (6) resulted.

A sensitivity analysis performed on the VAICOR model indicated that the only significant source of 
temperature correction to be applied to night flights comes from the lag term in the heat balance equation. An accurate prediction of the lag correction term requires a knowledge of the mass and specific heat of the capacitive bead. Because the aluminized coating has a very low emissivity, it is transparent to infrared radiation and thus, the absorption and emission terms are not influenced by nighttime infrared radiation. Consequently, cloud cover, surface temperature, and albedo are not sources of temperature error in nighttime RS-80 flights.

The daytime temperature correction is sensitive to solar angle, cloud cover, and changes in the convective heat transfer coefficient that result from changes in the balloon rise rate. These parameters are known, or can be modeled to approximately the same degree of accuracy as for the VIZ sonde. The estimated accuracy of the VAICOR correction profiles for the RS-80 sonde is similar to that of the VIZ; approximately $\pm 0.3^{\circ} \mathrm{C}$.

\section{Comparison of Corrected Temperature Profiles}

Data from the Potential REFerence RadioSonde (PREFRS) intercomparison was used to derive temperature correction profiles for the RS-80, VIZ, and AIR multi-thermistor radiosondes. These correction profiles have been applied to the measured temperatures to arrive at corrected, or true, atmospheric temperature profiles. If the corrected profiles from all radiosondes agree then the atmospheric temperature is accurately known, since the correction techniques are largely independent, and the significant error sources differ between the 3-thermistor and the VIZCOR and VALCOR model correction techniques. Furthermore, when one or more profiles is in disagreement, the profile in error can often be determined. This multi-comparison of corrected radiosonde profiles provides an excellent method of assessing the absolute accuracy of radiosonde profiles. It also provides a standardized reference technology for assessing the accuracy of other radiosonde instruments.

Four day flights and four night flights from the PREFRS data set were used in the evaluation. Each flight contained a VIZ 3-thermistor radiosonde, an AIR 3-thermistor radiosonde, and a Vaisala RS-80 
radiosonde. These three radiosondes generated 5 corrected temperature profiles. The flight conditions included clear, partially cloudy and overcast conditions, cirrus clouds, and solar strength angles between 55 and 87 degrees.

Before running the VAICOR model on the RS-80 sonde the Vaisala sonde data had to be uncorrected by removing the factory radiation correction that is applied in the VAISALA data reduction software. In removing this correction it was necessary to calculate the ventilation factor, $k$, which empirically corrects for the change in the convective heat transfer coefficient of the thermistor as the rise rate of the balloon varies. After the RS-80 data was uncorrected, the VAICOR correction was added, and the corrected RS- 80 data was then compared with the other profiles. Plots were made of each of the five correction profiles, and of the difference between the corrected VAISALA vs corrected VIZ, and corrected VAISALA vs corrected AIR profiles. For the sake of completeness, plots were also made showing the RS80 factory correction vs the RS-80 VAICOR correction.

\section{NIGHTFLIGHTS:}

The four night flights provided valid data from all radiosonde sensors so that comparisons could be made. Figures $2-6$ show selected plots from the analysis of night flight 006 . Figure 2 shows the VAICOR correction for the Vaisala RS-80 sonde. Also shown is the factory correction that is applied in the Vaisala software. The factory correction is known to overestimate the night time temperature error at higher altitudes. The VAICOR correction is variable and less than 0.5 degrees at all altitudes. The source of this correction is the thermal lag of the thermistor. When the temperature gradient is negative, from the surface to about $10 \mathrm{~km}$ the lag error is positive, that is the thermistor temperature is warmer than that of the ambient atmosphere. Above $30 \mathrm{~km}$ a positive temperature gradient exists. There is no factory lag correction that is included in the Vaisala RS-80 software. Other than the temperature lag, there are no other heat sources that introduces significant error into the night time RS-80 temperature measurement.

Figures 3 and 4 show the VIZCOR model and 3-thermistor measured temperature correction 
profiles for the AIR and VIZ radiosondes. The VIZCOR profile includes significant contributions from absorbed and emitted Infrared radiation as well as the thermal lag. From Figures 3 and 4, it is seen that agreement between 3 of the 4 profiles is excellent while the measured 3-thermistor AIR sonde profile is bias on the warm side by about 0.3 degrees. A likely source of this bias is a bias in the calibration, or temperature sensing, of one of the three coated rod thermistors.

Figure 5 compares the corrected Vaisala RS-80 with the AIR and VIZ 3-thermistor measured and VIZCOR predicted profiles. The Vaisala RS- 80 profile is used as reference, with all other profiles subtracted from the corrected RS- 80 Profile. The high frequency variability seen in the profiles is primarily the result of the random error in the temperature measurements of the Vaisala sonde since the other 4 sondes largely follow the same small scale trends. The thermistors used on the AIR and VIZ sondes were in fact resistance matched to minimize in the temperature error. Where the difference between the corrected profiles is near zero it can be concluded that all corrected profiles are accurate. The fact that the 3-thermistor corrected profiles agree with the VIZCOR and VAICOR profiles gives corroborating evidence that all profiles are accurate in an absolute sense. From Figure 5 , it is seen that the corrected difference profiles oscillate about zero from the surface to about $25 \mathrm{~km}$. Above this altitude the corrected RS- 80 profile is slightly warmer than the other corrected profiles. The fact that the AIR corrected difference profile shows a negative bias of about 0.40 between 5 and 10 kilometers not seen in the VIZ corrected difference profiles is because the temperature measurements themselves from these two sondes disagree in this region. This negative trend in the AIR profile has been found to be due to a timing bias in the data reduction procedure that introduced a spurious lag error in the temperature measurements. This timing bias is being removed in the AIR data processing software. Thus, from a careful analysis of the plots of Figures $2-5$ one can deduce not only the agreement between measurements from the three sensors but also a likely source of error when the profiles do not agree.

Each of the remaining (3) night flights were analyzed in the same manner as above. The corrected difference profiles are shown for each flight and each radiosonde in Figures 6-8. The environmental conditions for these flights included cloud cover and cirrus clouds. Although cloud cover does not influence 
the nighttime temperature of the Vaisala RS-80 sonde it does influence the temperature of the rod thermistor used on both the VIZ and AIR sondes. Where cloud cover exists the model only calculates the temperature correction above the cloud top altitude. All three night flights show excellent agreement in the temperature profiles from the three sondes up to $30 \mathrm{~km}$. Above $30 \mathrm{~km}$ the corrected RS-80 temperature becomes warmer than the AIR and VIZ temperatures by about 1 degree at $35 \mathrm{~km}$. The cause of this disagreement is not yet known.

\section{DAYFLIGHTS}

The corrected profiles from 4 day flights were compared in the same manner as for the night flights. The environmental conditions for these flights included clear sky, partial cloud cover, overcast, and a dense layer of cirrus clouds. Solar Zenith angles from 87 to 55 degrees occurred throughout these flights. The solar angle and daytime cloud cover influence the thermistor temperature for all three radiosondes. Thus, agreement between corrected profiles under this range of conditions would imply that the cloud cover and solar angle corrections are accurate for each instrument.

Figures 9-12 show the individual correction profiles, and the corrected difference profiles for the clear sky day flight 012 . The 3-Thermistor and VIZCOR model correction profiles, Figures 10 and 11 show agreement in the mean to within about $0.2^{\circ} \mathrm{C}$ at all altitudes. The difference between corrected temperature profiles, Figure 12 also show excellent agreement up to $30 \mathrm{~km}$. Above $30 \mathrm{~km}$ the RS-80 sonde again tends to be warmer than the VIZ and AIR sondes. Also the consistent bias from 5 and $10 \mathrm{~km}$ seen in the AIR profiles is the result of the timing error in the AIR sonde.

For the day flight 031 there existed overcast conditions at $2.5 \mathrm{~km}$. The corrected difference profiles (Figure 13) shows good agreement to $30 \mathrm{~km}$, with the same trend seen above this altitude. The 3 thermistor VIZ sonde did not provide accurate data for this flight.

Day flights 025 and 045 include the influence of a layer of cirrus clouds. The corrected difference profiles from these flights, Figures 13-14, show the same type of agreement as the other flights. 


\section{Conclusions}

Three largely independent methods have been used to derive the temperature of the atmosphere from the temperature measured by the thermistor(s) on 3 different radiosondes. These three radiosondes provided 5 atmospheric temperature profiles that were compared by differencing each of the four corrected profiles from the corrected Vaisala RS-80 profile. The corrected temperature profiles were found to be in excellent agreement up to $30 \mathrm{~km}$ from all three instruments in both daytime and night time fight conditions. The flight environments included total and partial cloud cover, cirrus clouds, and daytime solar zenith angles from 60 to 87 degrees. Above $30 \mathrm{~km}$, the corrected Vaisala RS-80 temperature tends to be warmer than the other sondes. The cause of this disagreement is not yet known.

Agreement in corrected temperatures between the three independent methodologies gives strong evidence that the difference in corrected profiles represents the absolute accuracy of the measurements. The corrected profiles appear to be unbiased (up to $30 \mathrm{~km}$ ) with a random component of error on the Vaisala system of about $0.5^{\circ} \mathrm{C}$ and less than $0.2^{\circ} \mathrm{C}$ for the VIZ and AIR sondes equipped with the resistance matched thermistors.

The VIZCOR and VAICOR models are shown to provide an accurate method of correcting the temperature measurements of the NWS VIZ sonde and the Vaisala RS- 80 sonde provided the environmental flight conditions are known. The environmental flight condition of significance to the Vaisala sonde are solar angle and cloud cover, including cirrus clouds. For the VIZ sonde, the surface temperature is an additional significant environmental parameter. Thus, it is possible not only to operationally correct radiosonde measurements but also to correct historical profiles provided cloud cover, solar angle, and surface temperature can be deduced about the observation. By correcting historical profiles a data base of compatible, and unbiased temperature profiles can be developed from worldwide locations that have utilized the VIZ and RS-80 radiosondes. 


\section{ACKNOWLEDGEMENTS}

The authors wish to thank Dr. John Nash and Mr. Francis Schmidlin for furnishing the PREFRS intercomparison data. Appreciation is also extended to the VIZ and Vaisala companies for furnishing technical information which made this study possible. James Luers is supported to NOAA contract No. 50EANE-2-00077. Bert Eskridge is employed by the National Climatic Data Center. The CARDS project is supported by the Department of Energy under contract DE-Al05-90ER61011, the NOAA Climate and Global Change Program, and the National Climatic Data Center. 


\section{REFERENCES}

Antikainen, V., "Solar Radiation Error of Vaisala Radiosonde RS-18," Vaisala News, 57 (1973), Vaisala, Helsinki, Finland.

Ballard, H. N. and Rubio, R., "Corrections to Observed Rocketsonde and Balloonsonde Temperatures," Journal of Applied Meteorology, 7(5), pp. 919-928, October 1968.

Fan, D. R. and Keswani, K., "A Continuous Correlation Equation for Heat Transfer from Cylinders to Air in Crossflow for Reynolds Numbers from $10^{-2}$ to $2 \times 10^{5}$, Int J. Heat Mass Transfer, 15, pp. 559-562, 1972

Kneizys, F. X. et. al., "Users Guide to LOWTRAN7," Air Force Geophysics Laboratory AFGL-TR-88-0177, August, 1988.

Luers, J. K., "The Influence of Environmental Factors on the Temperature of the Radiosonde Thermistor," Ph.D. Dissertation, University of Tennessee, 1989. UMI \#9021036.

Luers, J. K., "Estimating the Temperature Error of the Radiosonde Rod Thermistor Under Different Environments," Journal of Atmospheric and Oceanic Technology, Vol. 7, No. 6., November/December 1990.

Luers, J. K., "Absolute Accuracy of the Multi-Thermistor Radiosonde for Measuring Atmospheric Temperature," University of Dayton UDR-TR-91-151, August 1992.

Luers, J. K., "Temperature Corrections for VIZ, Space Data, and Vaisala Radiosondes," University of Dayton UDR-TR-93-XX, July 1993. 
Luers, J. K. and Schmidlin, F., "Evaluation of Temperature Measurements from 3-Thermistor Reference Radiosonde," WMO Technical Conference on Instrumentation and Methods of Observation, Vienna, Austria, May 11-15, 1992.

Schmidlin, F. J., "Development and Application of a Reference Temperature Radiosonde," WMO TECO-92, Vienna, Austria, May 1992.

Schmidlin, F. J., Luers, J. K., and Huffman, P. D., "Preliminary Estimates of Radiosonde Thermistor Errors," NASA Technical Paper \#2637, 1986.

Schmidlin, F. J. and Luers, J. K., "Development and Application of Corrections to the U.S. Radiosonde Rod Thermistor Temperature Measurements," WMO Conference on Instruments and Methods of Observation, Leipzig, German Democratic Republic, May 16-20, 1988.

Talbot, J. E., "Radiation Influences on a White-Coated Thermistor Temperature Sensor in a Radiosonde," Australian Meteorology Magazine, Vol 20, pp. 22-33, March 1972.

Vaisala, Vilho, "Effects of Radiation Upon Measurements of Stratospheric Temperature," Vaisala News, 35 (1967), Vaisala, Helsinki, Finland.

Vaisala RS-80 Radiosonde Manufacturer's Brochure, Ref. NO. 435, Vaisala, Helsinki, Finland, September 1992. 
Figure 1. Vaisala RS-80, 4-thermistor VIZ and 3-thermistor AIR Sondes.

Figure 2. Vaisala RS-80 Correction; Night Flight 006.

Figure 3. VIZCOR Model Predicted vs 3-Thermistor Measured Profiles; AIR Sonde; Night Flight 006.

Figure 4. VIZCOR Model vs 3-Thermistor-Measured Profiles; VIZ Sonde; Night Flight 006.

Figure 5. Difference Between Corrected Profiles; Night Flight 006, Clear.

Figure 6. Difference Between Corrected Profiles; Night Flight 020, Clouds and Cirrus.

Figure 7. Difference Between Corrected Profiles; Night Flight 037, Partially Cloudy.

Figure 8. Difference Between Corrected Profiles; Night Flight 047, Clear.

Figure 9. Vaisala RS-80 Correction; Day Flight 012, Clear.

Figure 10. VIZCOR Model Predicted vs 3-Thermistor Measured Profiles: AIR Sonde; Day Flight 012, Clear.

Figure 11. VIZCOR Model Predicted vs 3-Thermistor Measured Profiles; VIZ Sonde; Day Flight 012, Clear.

Figure 12. Difference Between Corrected Profiles; Day Flight 012, Clear.

Figure 13. Difference Between Corrected Profiles; Day Flight 031, Overcast.

Figure 14. Difference Between Corrected Profiles; Dayflight 025, Cloud Cover and Cirrus.

Figure 15. Difference Between Corrected Profiles; Day Flight 045, Cloud Cover and Cirrus. 

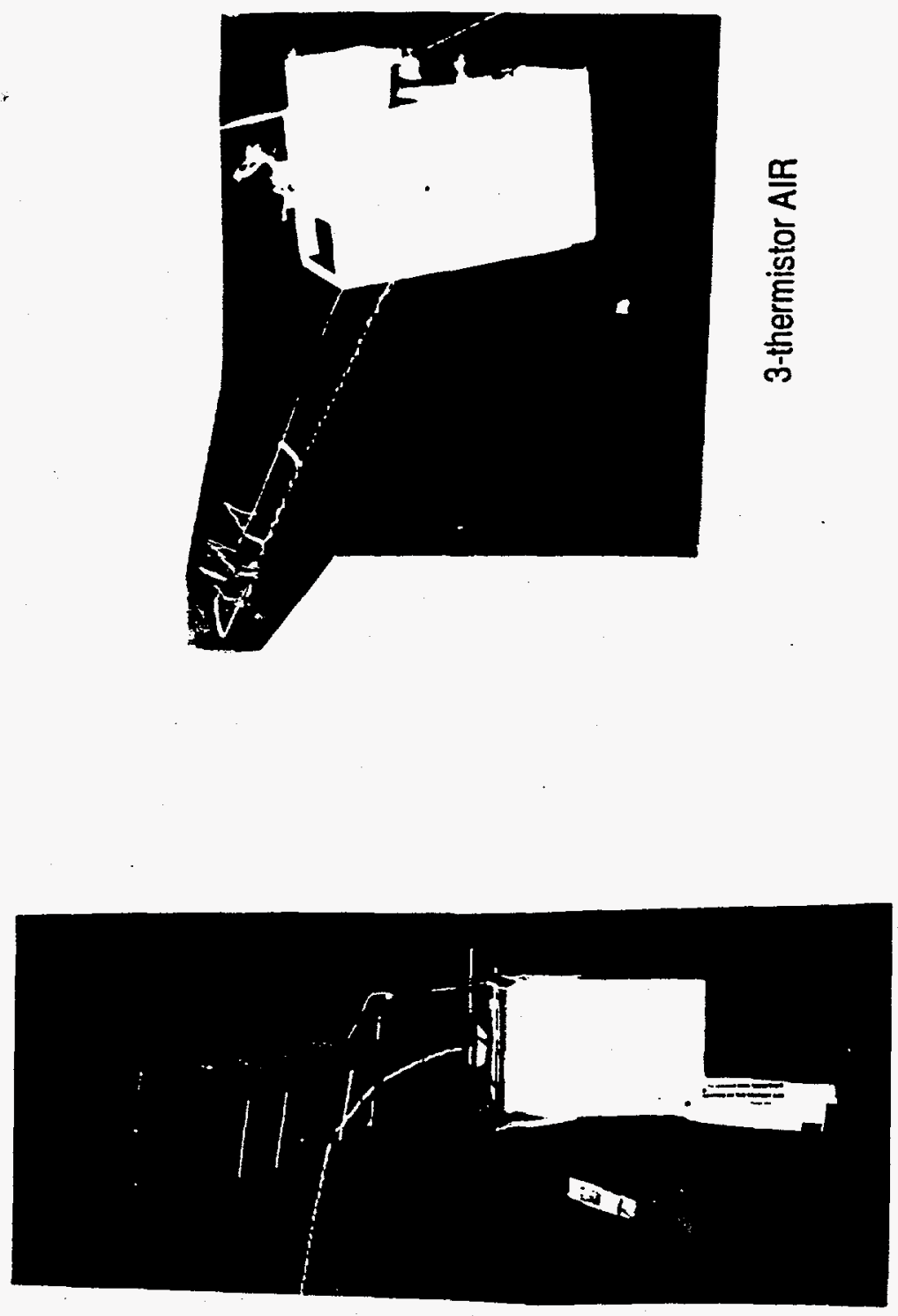

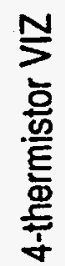

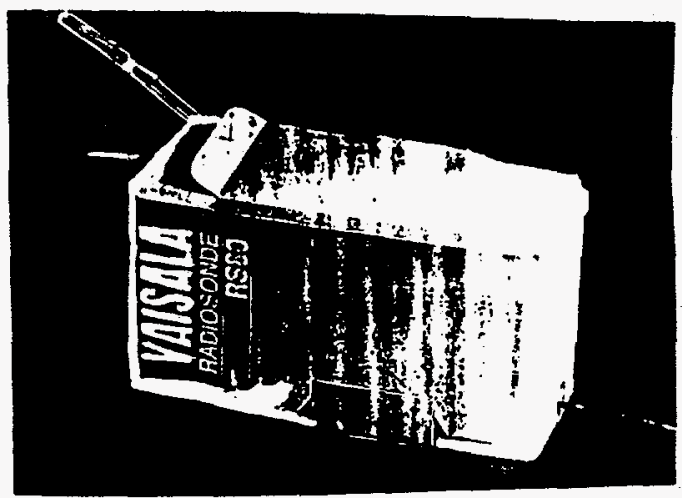

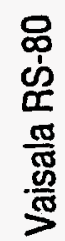




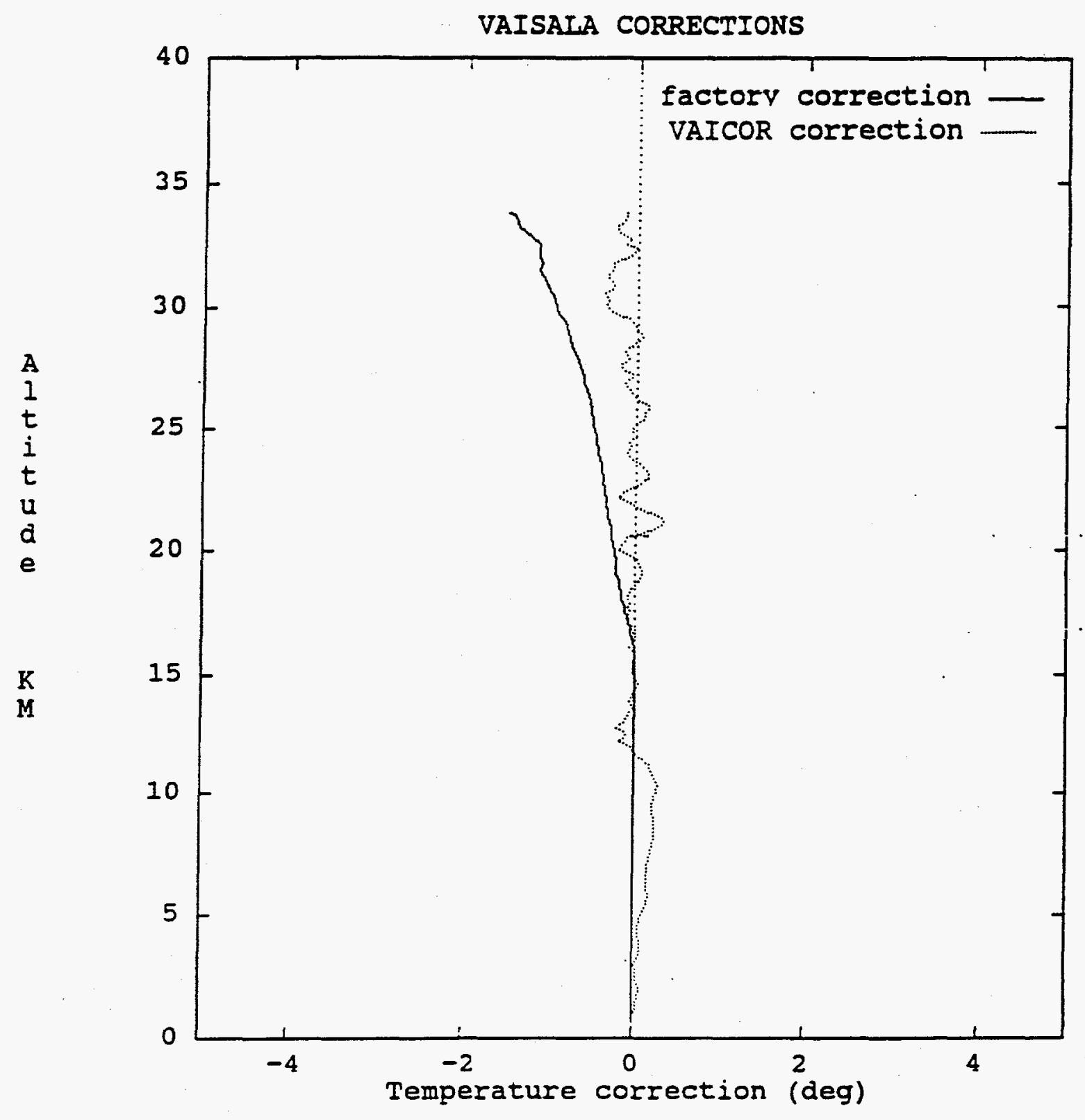




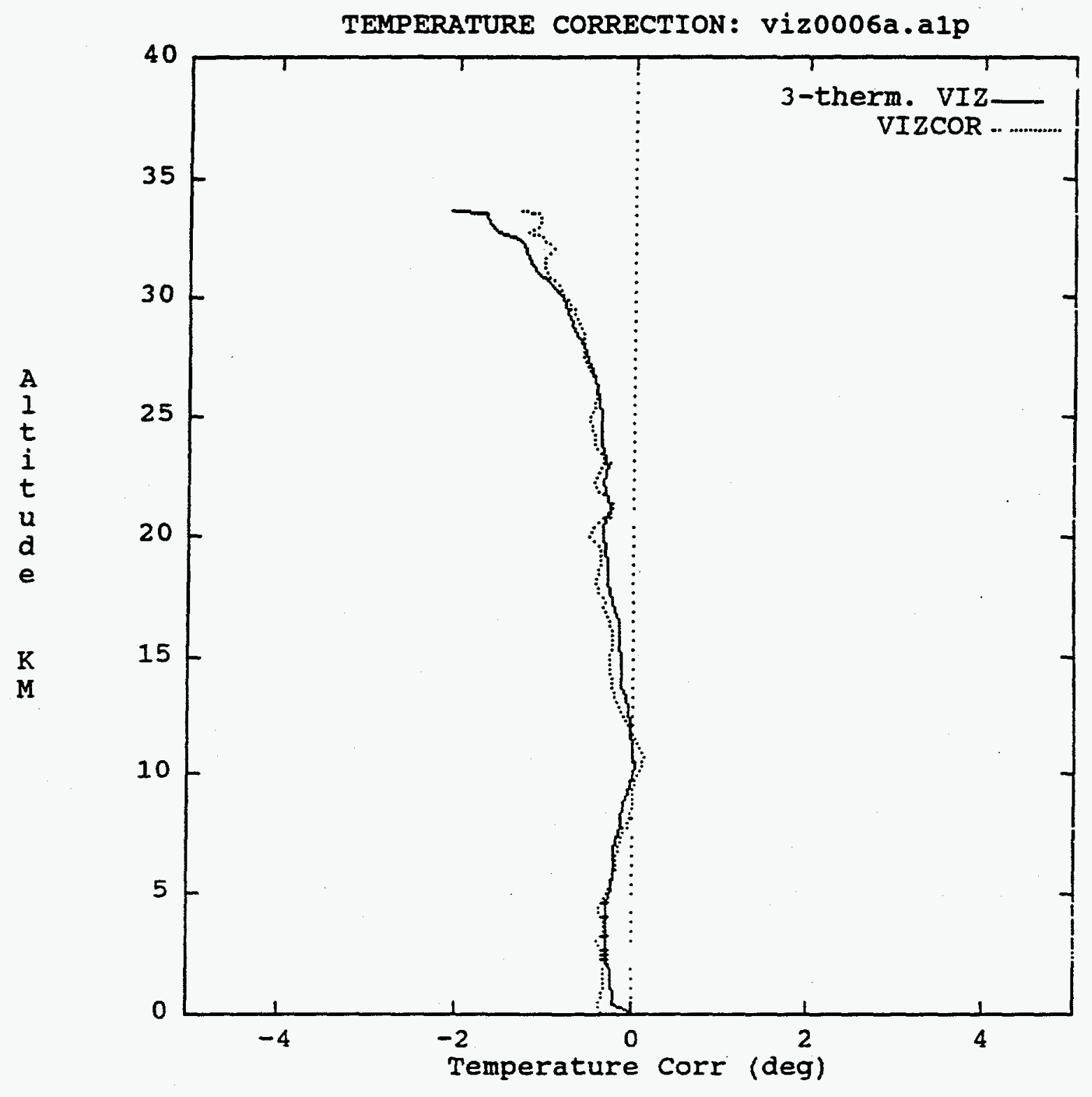




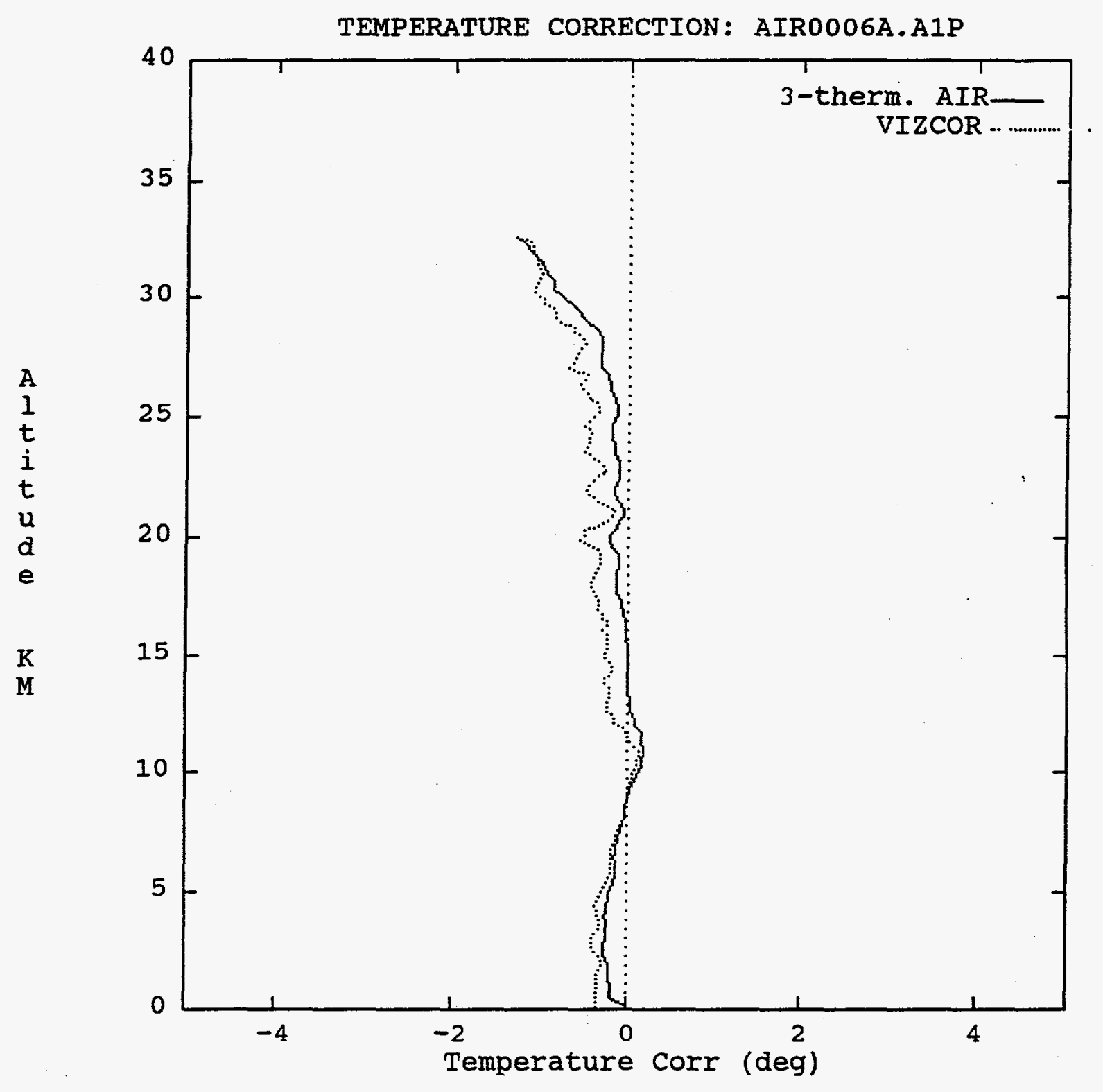




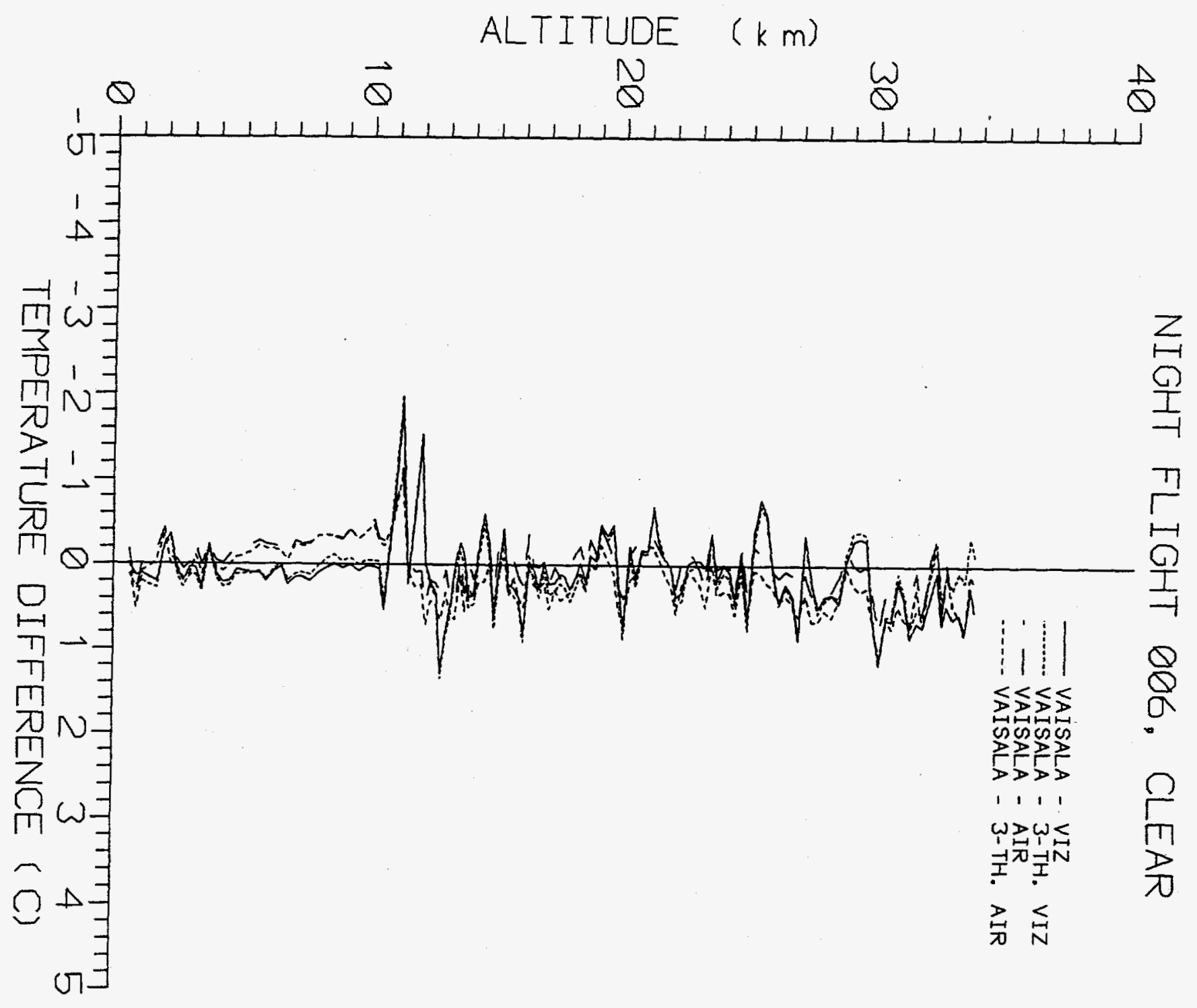




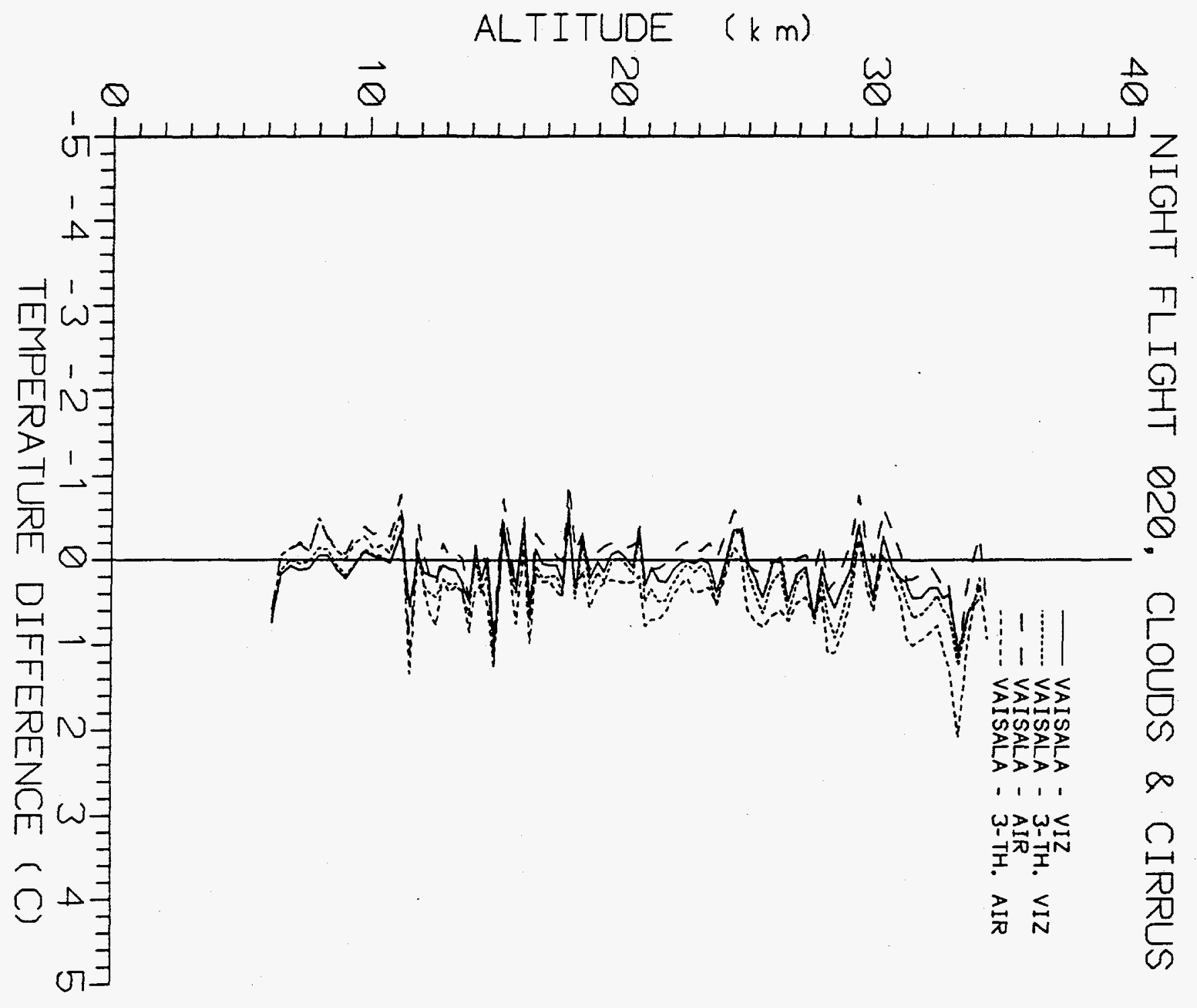




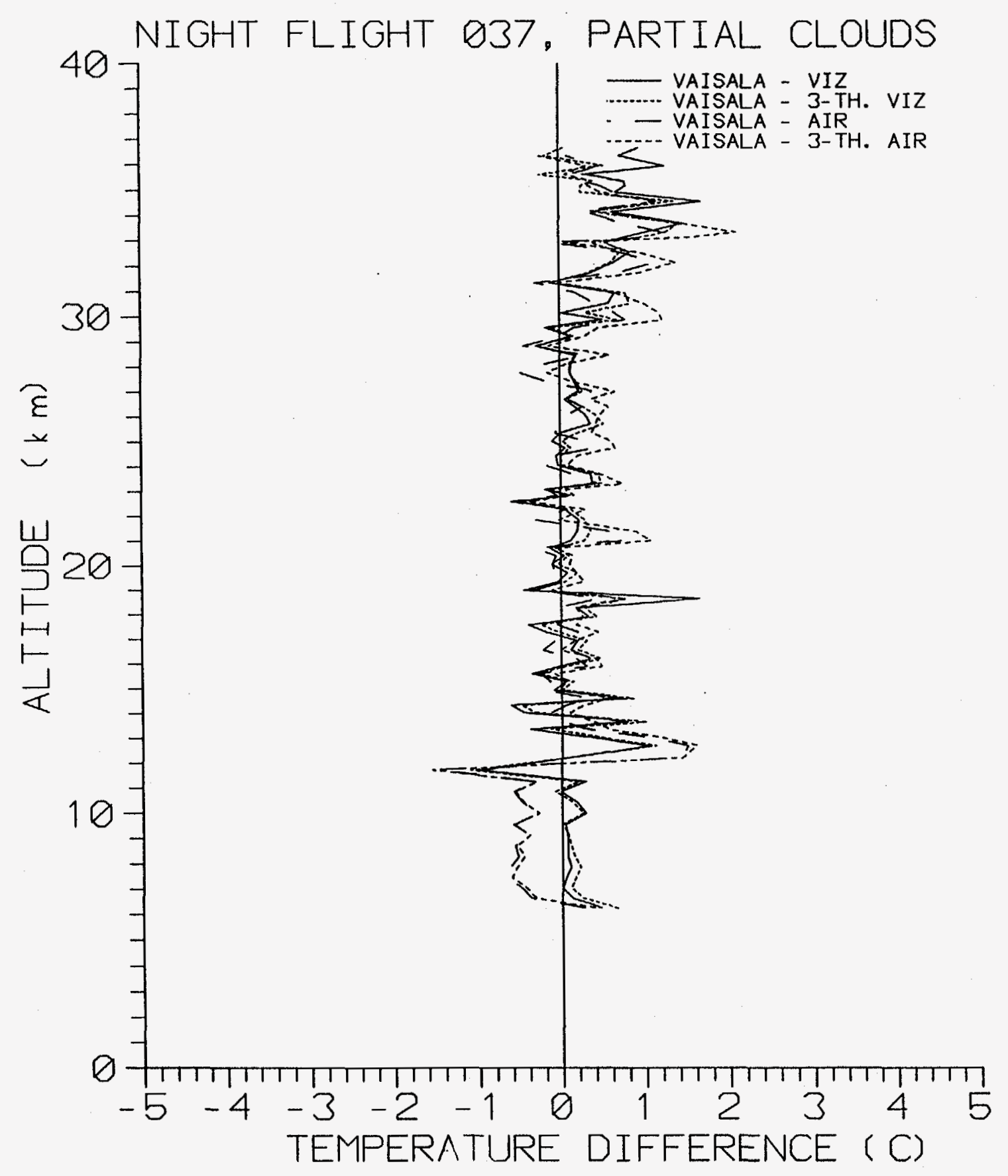




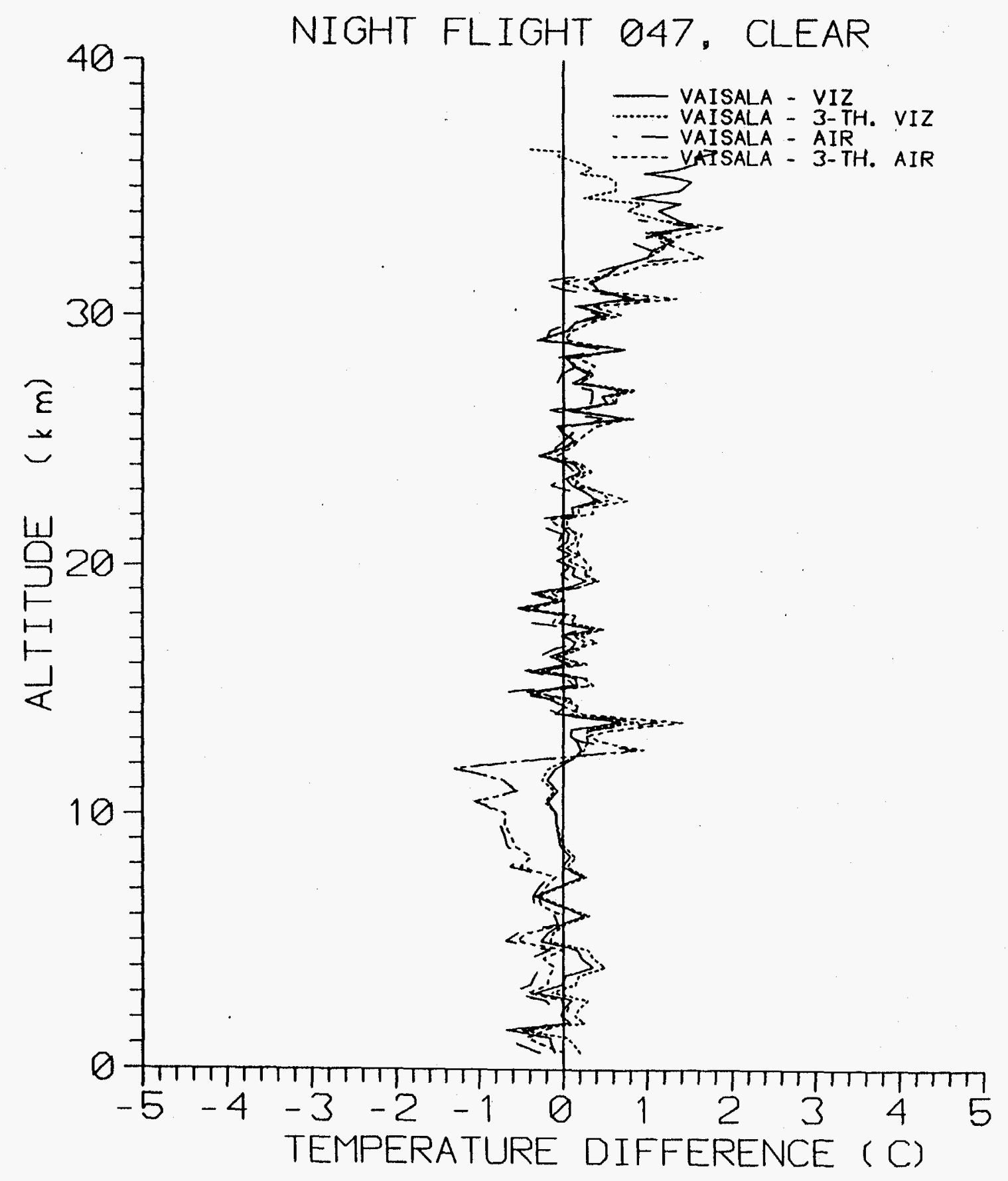




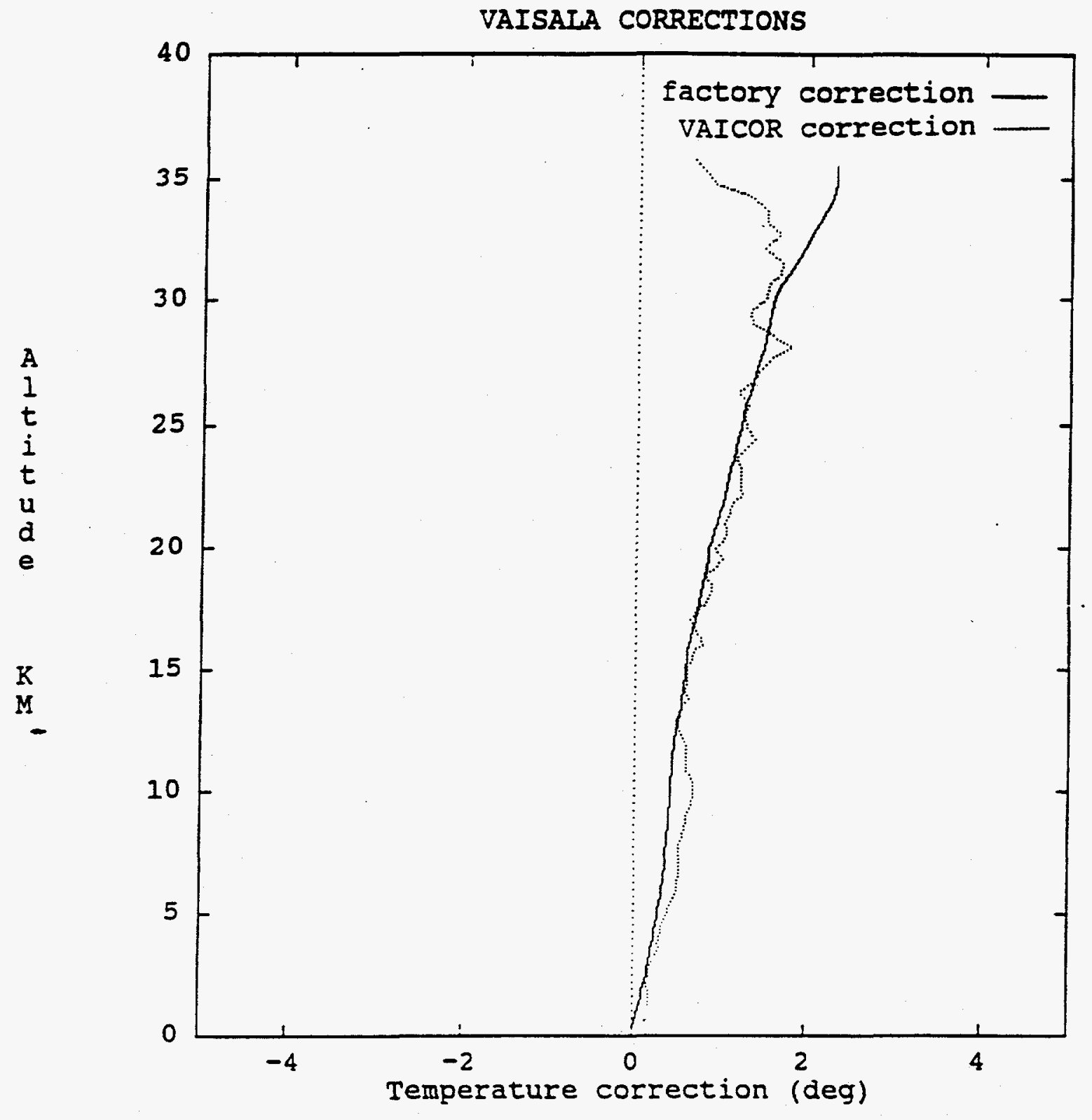




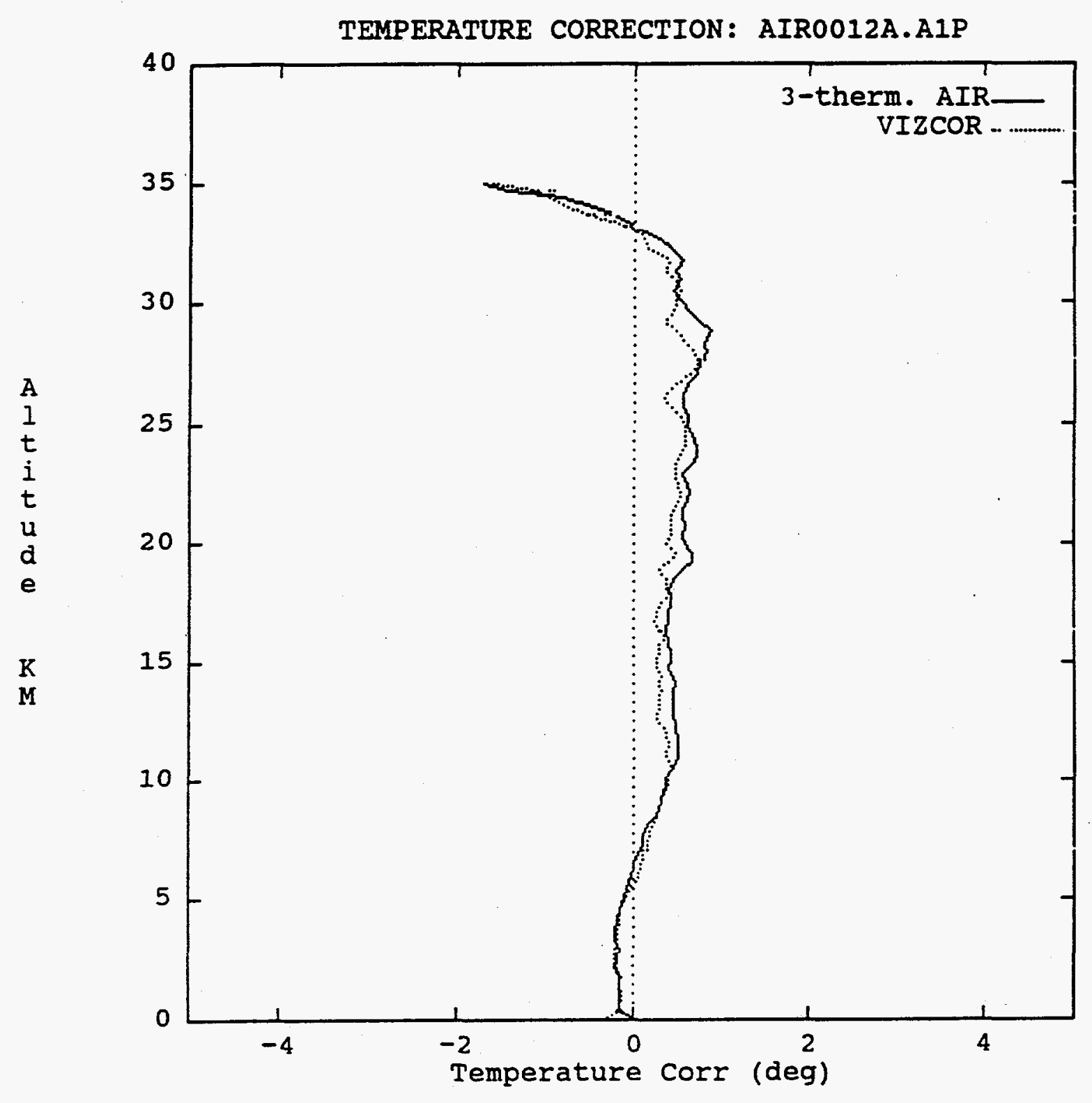




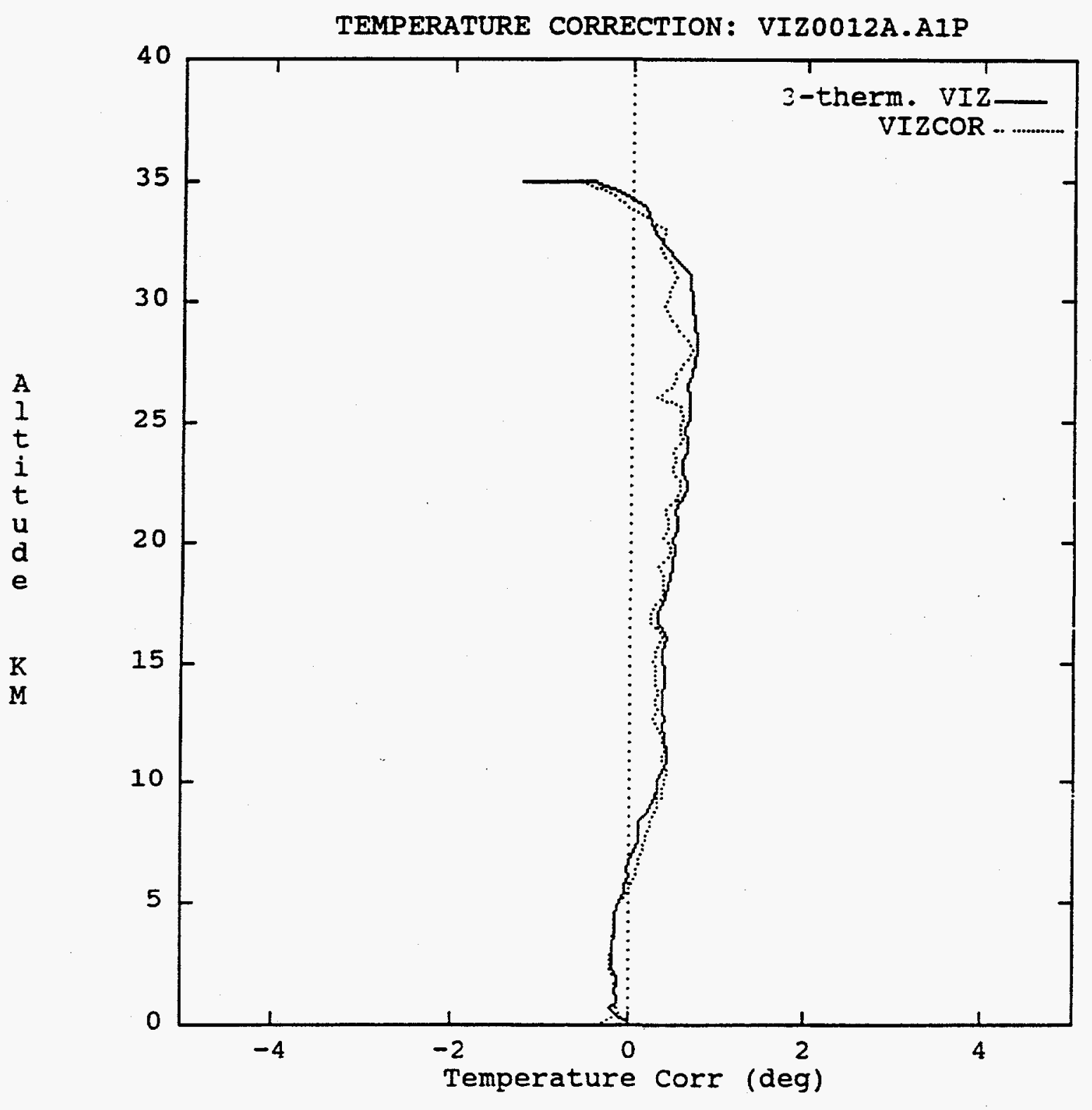




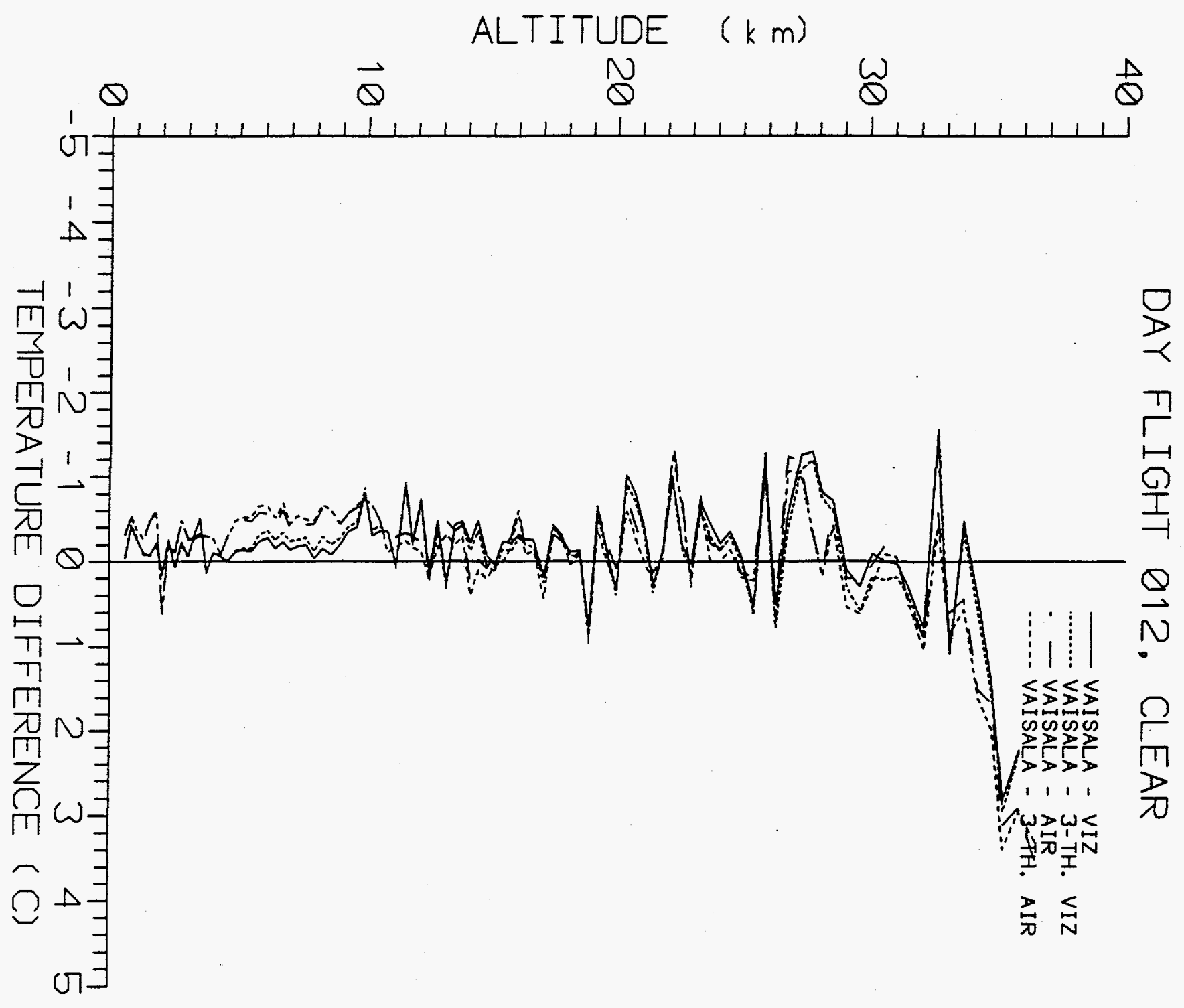




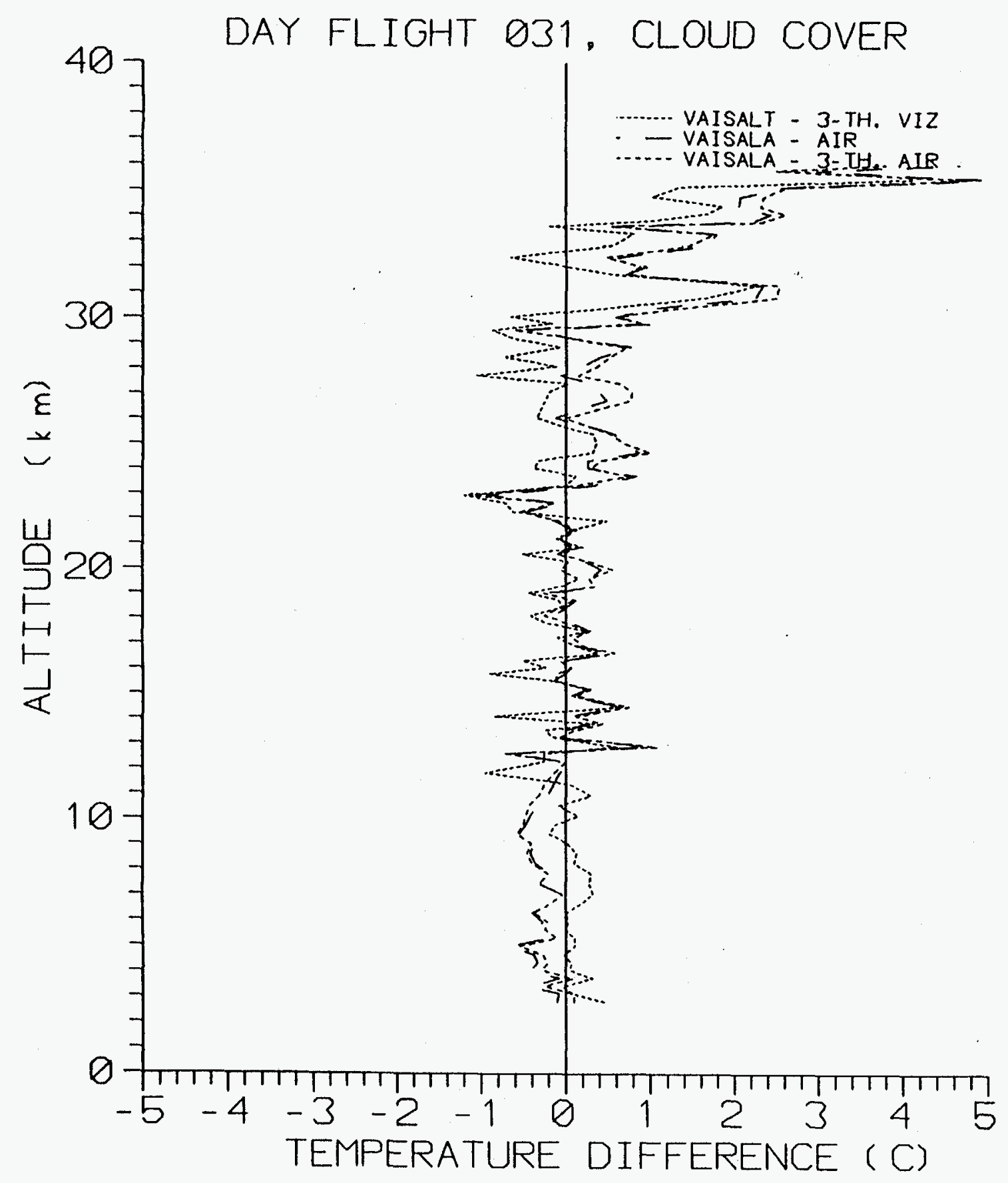




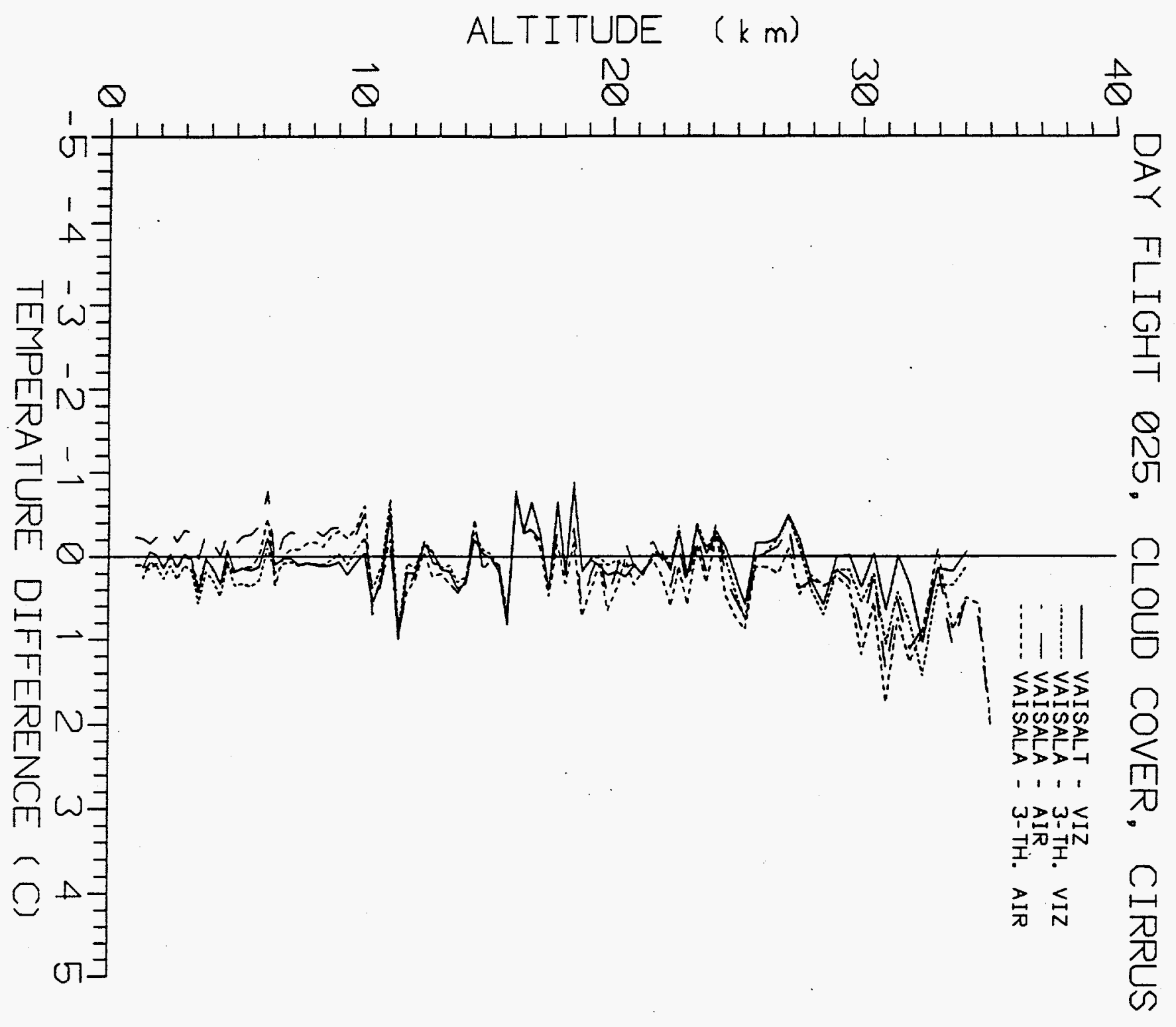




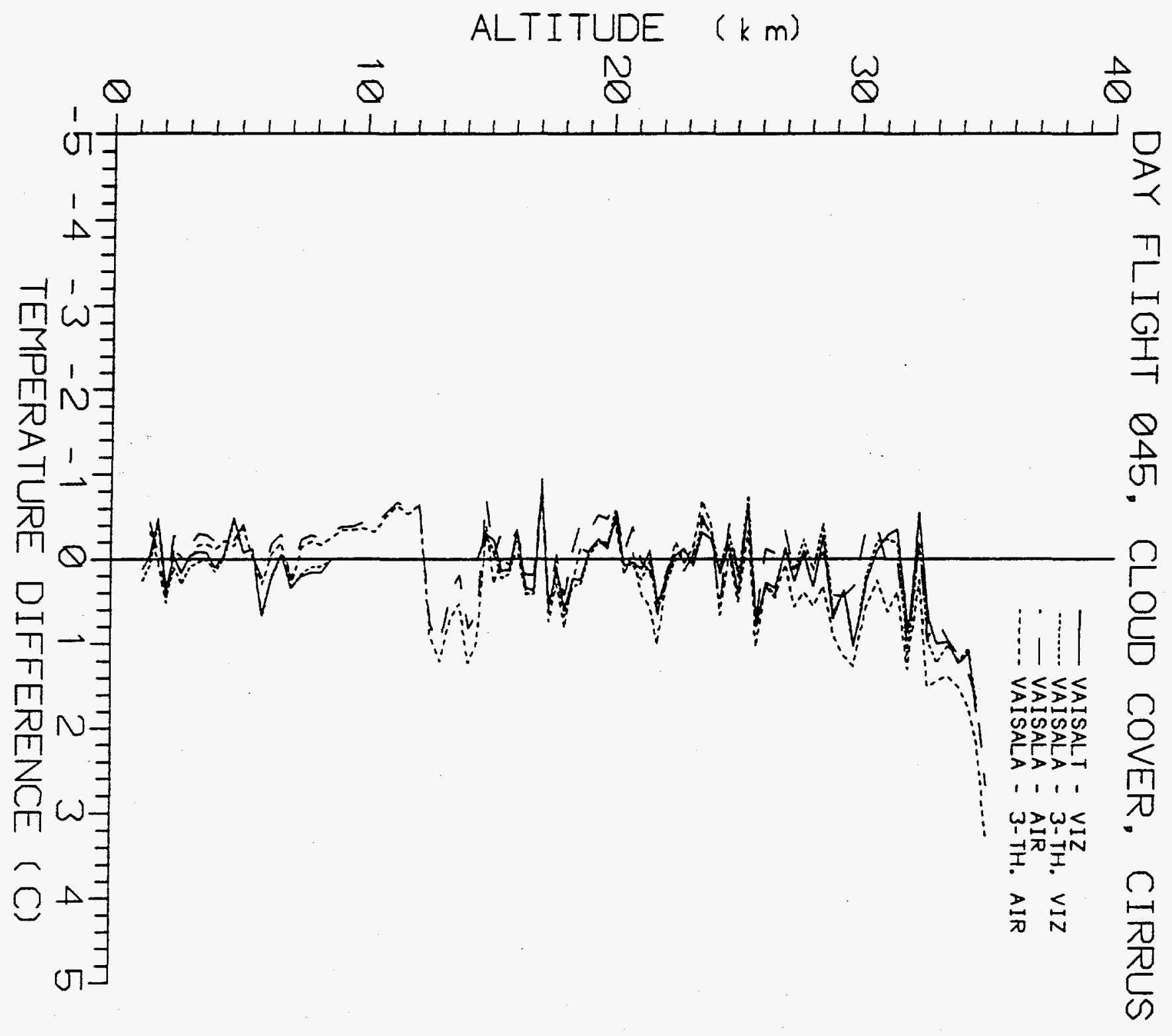

